\title{
Callogénesis in vitro de paprika (Capsicum annuum L.) cv. Papri King a partir de tallos
}

\author{
In vitro callogenesis of paprika (Capsicum annuum L.) cv. Papri King from stems
}

Alexis Argüelles Curaca1', Angel David Hernández Amasifuen¹, Anthony Apolinario Cortez Lazaro', Hermila Belba Díaz Pillasca

\section{RESUMEN}

Objetivo: Inducir a la ruta de callogénesis in vitro de paprika (Capsicum annuum L.) cv. Papri King a partir de tallos. Material y Métodos: Se emplearon plantas de paprika germinadas in vitro, a las cuales se eliminó hojas y raíces, dejando solo el tallo como explante y fue introducido en cinco tratamientos de medio de cultivo MS con diferentes concentraciones de ácido giberélico, transcurrido los 35 días se evaluó el porcentaje de inducción de callos y tamaño de callos. Resultados: Se obtuvieron $66 \%$, $84 \%$, $93 \%, 91 \%$ y $82 \%$ de inducción de callos a partir de los tratamientos T1, T2, T3, T4 y T5 respectivamente, además los tratamientos T3 y T4 fueron los que lograron formar mayor tamaño de callos. Conclusión: Se logro inducir a la ruta de callogénesis in vitro de paprika cv. Papri King a partir de tallos, obteniendo $93 \%$ y $91 \%$ de inducción de callos con los medios de cultivo MS adicionado con 1 (T3) y 1,5 (T4) mg/L de ácido giberélico respectivamente

Palabras claves: Capsicum annuum, paprika, Papri King, callogénesis.

\section{ABSTRACT}

Objective: Induce the path in vitro callogenesis of paprika (Capsicum annuum L.) cv. Papri King from stems. Materials and Methods: Germinated paprika plants were used in vitro, to which leaves and roots were removed, leaving only the stem as an explant and was introduced in five treatments of MS culture medium with different concentrations of gibberellic acid, after 35 days The percentage of callus induction and callus size was evaluated. Results: $66 \%, 84 \%, 93 \%, 91 \%$ and $82 \%$ of callus induction were obtained from treatments T1, T2, T3, T4 and T5 respectively, in addition the treatments T3 and T4 were the ones that managed to form the greatest callus size Conclusion: It was possible to induce the pathogenesis pathway in vitro of paprika cv. Papri King from stems, obtaining $93 \%$ and $91 \%$ of callus induction with MS culture media added with 1 (T3) and 1.5 (T4) mg/L of gibberellic acid respectively.

Keywords: Capsicum annuum, paprika, Papri King, callogenesis.

\section{INTRODUCCIÓN}

En Perú existe una gran variedad de especies del género Capsicum que son cultivadas en distintas regiones del país para el consumo personal, pero en mayor parte para exportación. Elevando año tras año la productividad de especies y cultivares del género Capsicum, de esta manera llegando Perú a ocupar el puesto veintisiete a nivel mundial como productor y octavo exportador a nivel mundial de Capsicum (ADEX, 2017).

Dentro de las especies de Capsicum de mayor exportación de Perú se encuentra el ají paprika (Capsicum annuиm L.), ubicando como el segundo mayor exportador de ají paprika a nivel mundial, tras ser desplazado del primero lugar por China a partir del 2012. Por lo que este cultivo se ha convertido en uno de los de mayor importancia en la costa peruana, siendo el valle e irrigaciones de Barranca el principal productor de ají paprika en la costa central, por presentar zonas de temperaturas uniformes sin fluctuaciones entre día y noche, permitiendo obtener un rendimiento mayor de producción por hectárea (Alarco y Patiño, 2008; ADEX, 2017).

La paprika presenta diferentes cultivares, pero los que presentan más áreas de cultivo y demanda son los cultivares Papri King, Papri Queen y Sonora, de las cuales Papri King es la preferida por los agricultores en las zonas productoras de Barranca, debido a que presenta un fruto de mayor taño, pared delgada y capacidad de secado muy bueno (Valerio, 2016).

En la actualidad se reportan descensos en el rendimiento por hectárea de los cultivos de paprika en el país, debido a enfermedades producidas por fitopatógenos presentes en los suelos. Los hongos fitopatógenos más relacionados al cultivo de paprika son Fusarium oxysporum., Phytophthora capsici y Rhizoctonia solani. Estos en su mayoría son diseminados por semillas y plantines contaminados, también por el riego por gravedad, así como maquinarias que hacen heridas en las raíces de las plantas lo que permite el ingreso de estos patógenos (Arias, 2015; Romero, 2018; Hernández, Pineda y Córdova-Noriega).

El cultivo de paprika también se ve afectado por la baja disponibilidad de semillas certificadas, debido a que los agricultores en el mayor de los casos emplean semillas de cosechas anteriores por los elevados costos de las semillas de calidad, de tal manera sus cultivos se ven afectados desde la variación de cada planta en referencia a tamaños, productividad y calidad de sus frutos de paprika (Vilca, 2008; Pech et al., 2010).

El cultivo in vitro de tejidos vegetales se presenta como una excelente alternativa para superar las dificultades del manejo tradicional en la producción de una amplia gama de especies, ya que por medio de esta técnica es posible clonar individuos con alto valor genético, también en conseguir plantas de alta calidad que pueden llegar incluso a triplicar las ganancias económicas y, además, obtener material vegetal libre de patógenos (Sanatombi y Sharma, 2007; Barnicoat, Cripps y Kendon).

Aprovechando la totipotencia celular se puede regenerar una planta a partir de cualquier explante inicial, siguiendo rutas organogénicas, las cuales pueden inducir a la formación de órganos (organogénesis), mediante callos 
(callogénesis) o raíces (rizogénesis); además también se puede seguir la ruta embriogénica, en la cual se induce la formación de embriones somáticos (embriogénesis).

Para ambas rutas, de forma indirecta se requiere una fase en la que exista una elevada división celular desorganizada, de esta manera se forman masas de células indiferenciadas denominadas callos (Avilán, Leal y Bautista, 1992; Segretín, 2006; Hernández y Díaz, 2019).

Por lo tanto, el objetivo del presente estudio fue inducir a la ruta de callogénesis in vitro de paprika (Capsicum annuи $\mathrm{L}$.) Cv. Papri King a partir de tallos.

\section{MATERIAL Y MÉTODOS}

La presente investigación se llevó a cabo en el Laboratorio de Biotecnología Vegetal, perteneciente a Biología con mención en Biotecnología, Universidad Nacional José Faustino Sánchez Carrión, Huacho, Lima, Perú. Todos los medios de cultivos empleados en la investigación estuvieron conformados por las sales descritas por Murashige y Skoog (1962), adicionada con vitaminas (Tabla 1) y el pH fue ajustado a 5,8 empleando hidróxido de potasio $(\mathrm{KOH}) 1 \mathrm{~N}$ y ácido clorhídrico $(\mathrm{HCl}) 1$ N.

Tabla 1

Composición del medio de cultivo Murashige y Skoog (MS).

\begin{tabular}{lccc}
\hline \multicolumn{1}{c}{ Componentes } & $\begin{array}{c}\text { Concentración } \\
(\mathbf{m g} / \mathbf{L})\end{array}$ & Componentes & $\begin{array}{c}\text { Concentración } \\
(\mathbf{m g} / \mathbf{L})\end{array}$ \\
\hline $\mathrm{KNO}_{3}$ & 1900 & $\mathrm{KI}$ & 0,83 \\
$\mathrm{NH}_{4} \mathrm{NO}_{3}$ & 1650 & $\mathrm{Na}_{2} \mathrm{MoO}_{4} \cdot 2 \mathrm{H}_{2} \mathrm{O}$ & 0,25 \\
$\mathrm{CaCl}_{2}$ & 332,2 & $\mathrm{CoCl}_{2} \cdot 6 \mathrm{H}_{2} \mathrm{O}$ & 0,025 \\
$\mathrm{MgSO}_{4}$ & 180,7 & $\mathrm{CuSO}_{4} \cdot 5 \mathrm{H}_{2} \mathrm{O}$ & 0,025 \\
$\mathrm{KH}_{2} \mathrm{P} \mathrm{O}_{4}$ & 170 & Glicina & 2 \\
$\mathrm{C}_{10} \mathrm{H}_{14} \mathrm{~N}_{2} \mathrm{Na}_{2} \mathrm{O}_{8} 2 \mathrm{H}_{2} \mathrm{O}$ & 37,26 & Mioinositol & 100 \\
$\mathrm{FeSO}_{4} \cdot 7 \mathrm{H}_{2} \mathrm{O}$ & 27,8 & Ácido nicotínico & 0,5 \\
$\mathrm{MnSO}_{4} \cdot \mathrm{H}_{2} \mathrm{O}$ & 16,9 & Piridoxina HCL & 0,5 \\
$\mathrm{ZnSO}_{4} \cdot 7 \mathrm{H}_{2} \mathrm{O}$ & 8,6 & Tiamina HCL & 0,1 \\
$\mathrm{H}_{3} \mathrm{BO}_{3}$ & 6,2 & Ácido Naftalenacético & 1
\end{tabular}

El material vegetal empleado fueron tallos de paprika, los cuales se obtuvieron a partir de plántulas que fueron germinados in vitro siguiendo el protocolo establecido por Hernández, Pineda y Díaz (2019). Eliminándose hojas y raíces, dejando solo el tallo como explante, luego se introdujo un explante por tubo de ensayo con medio de cultivo MS, el cual además fue establecido en diferentes tratamientos para inducir a callogénesis (Tabla 2). Los explantes estuvieron durante 35 días a temperatura de $25 \pm 1{ }^{\circ} \mathrm{C}, 75 \%$ de humedad, fotoperiodo de 16 horas de luz con intensidad lumínica de 1500 lux.

\section{Tabla 2}

Tratamientos del medio de cultivo in vitro para explantes de paprika.

\begin{tabular}{cc}
\hline Tratamiento & $\begin{array}{c}\text { Concentracion } \\
\text { de Ag3 }(\mathrm{mg} / \mathrm{L})\end{array}$ \\
\hline T1 & 0 \\
T2 & 0,5 \\
T3 & 1 \\
T4 & 1,5 \\
T5 & 2,0 \\
\hline Ag3= Ácido giberélico &
\end{tabular}

El diseño experimental fue al azar con un explante por tubo de ensayo, con 10 repeticiones por tratamiento. Durante el experimento evaluó el porcentaje de inducción de callos y tamaño de callos. Se empleó el paquete estadístico agricolae del software libre $R$ versión 3.6.1, donde se procesaron los datos mediante Análisis de Varianza (ANOVA) y Tukey ( $p \leq 0,05)$ para la comparación de medias.

\section{RESULTADOS}

La inducción de callos a partir de tallos de paprika se dio en todos los tratamientos, siendo los tratamientos T3 y T4 los produjeron mayor porcentaje de callos (Tabla 3) con $93 \%$ y $91 \%$ respectivamente, también fueron los tratamientos que proporcionaron callos de mayor tamaño (Figura 1).

Los tratamientos T3 y T4 no presentaron diferencia significativa tanto para el porcentaje de callos como para el tamaño de callos, mientras que los tratamientos T2 y T5 no presentaron diferencias significativas entre ellos en ambos casos, mostrando mayor tamaño de callos que el tratamiento T1 (Figura 2).

Tabla 3

Efecto del hipoclorito de sodio en la desinfección de los explantes de Passiflora foetida $\mathbf{L}$.

\begin{tabular}{ccc}
\hline Tratamiento & $\begin{array}{c}\text { Inducción de } \\
\text { callos }(\%)\end{array}$ & $\begin{array}{c}\text { Tamaños de } \\
\text { callos }\end{array}$ \\
\hline T1 & $67 \mathrm{c}$ & + \\
T2 & $84 \mathrm{~b}$ & ++ \\
T3 & $93 \mathrm{a}$ & +++ \\
T4 & $91 \mathrm{a}$ & +++ \\
T5 & $82 \mathrm{~b}$ & ++ \\
\hline
\end{tabular}




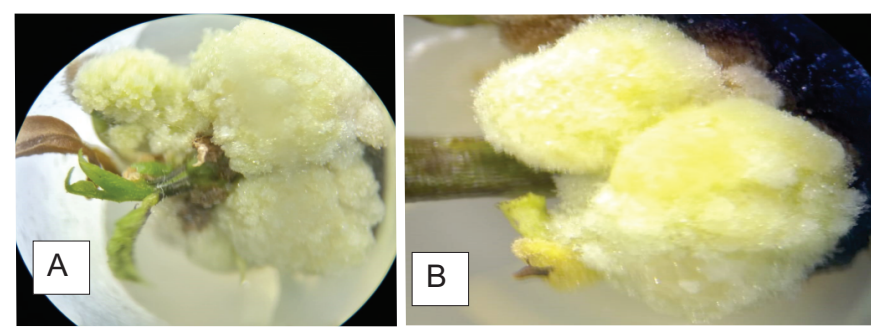

Figura 1. Callos inducidos a partir de tallos de paprika con los tratamientos T3 (A) y T4 (B), ambos tratamientos fueron los que mostraron mayor tamaño de los callos.

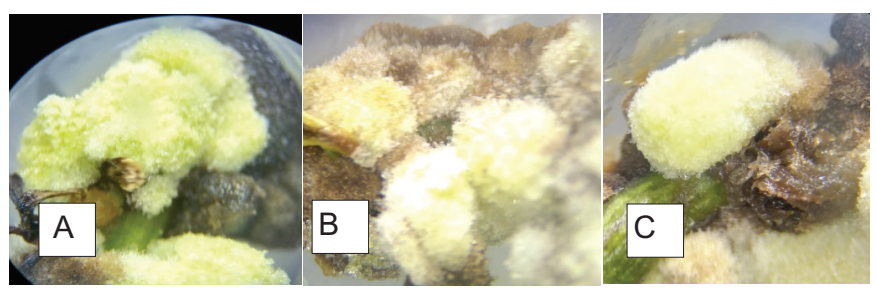

Figura 2. Los tallos de paprika empleados como explantes para la inducción de callos, formaron callos de menor tamaño en los tratamientos T2 (A) y T5 (B) a comparación de los mejores tratamientos, siendo el de menor tamaño el T1 c.

\section{DISCUSIÓN}

Los resultados de este estudio muestran que los tratamientos con mayor concentración de la fitohormona empleada indujeron mayor porcentaje de callos y también se observo un mayor crecimiento del tamaño de los callos, a excepción del T5 el cual demostró una leve inhibición, contrastando que la eficiencia del efecto de formación de callos disminuye al trabajar con altas concentraciones de la fitohormona (Jiménez, Chaparro Giraldo y Blanco, 2009; Hernández , Arguelles, Cortez y Diaz, 2020).

Esto ofrece un enfoque prometedor para la implementación de un protocolo el cual ofrece varias ventajas a partir de la ruta que se necesite en las futuras investigaciones, primero poder emplear estos callos en biorreactores para suspensiones celulares vegetales, así como también se puede emplear para embriogénesis somática o organogénesis, en ambos casos con la finalidad de producción de plantas completas, para esto es importante considerar la selección del explante, el medio y las condiciones de cultivo (Hall, Holden y Yeoman., 1988; Hernández et al., 2020).

También los resultados obtenidos nos dan una noción sobre las concentraciones adecuadas a emplear para la formación de callos puesto que la presencia de ácido giberélico en el medio de cultivo estimula la iniciación y formación de tallos adventicios, así como también actúa intensificando la respuesta a otros reguladores, favoreciendo la organogénesis, embriogénesis o como en el caso del presente trabajo la callogénesis (Ochatt y Caso, 1986).

El empleo de ácido giberélico en diferentes concentraciones intensifico el efecto del ácido naftalenacético como componente del medio de cultivo MS en todos los tratamientos que estuvo presente, como es el caso de muchas fitohormonas los cuales son componentes endógenos del explante en el medio de cultivo que logran dar inicio a la proliferación celular desorganizada en difrentes concentraciones o en combinación con otras fitohormonas, tal y como confirma lo descrito por Rabindra et al (2003), en que el uso de fitohormonas es favorable para la inducción de callos al determinar la concentración correcta o la combinación correcta de estas.

\section{CONCLUSIONES}

Se logro inducir a la ruta de callogénesis in vitro de paprika (Capsicum annuum L.) cv. Papri King a partir de tallos, obteniendo $93 \%$ y $91 \%$ de inducción de callos con los medios de cultivo MS adicionado con 1 y $1,5 \mathrm{mg} / \mathrm{L}$ de ácido giberélico, respectivamente.

\section{REFERENCIAS BIBLIOGRÁFICAS}

ADEX, Perú. (2017). Nota de prensa. Disponible en línea: http://www.adexperu.org. pe/notadeprensa/ lambayeque-es-la-primera-region-productora-decapsicum-en-peru/

Alarco, C. y Patiño, R. (2008). Evaluación de calidad y rendimiento en la extracción y caracterización de oleorresina de ají paprika (Capsicum annuum L.): Papriking y Sonora. Tesis de ingeniería, Universidad Nacional del Centro del Perú, Huancayo, Perú.

Arias, R. (2015). Identificación, incidencia y ocurrencia poblacional de enfermedades encontradas en dos variedades de pimiento (Capsicum annuum L.) para agroexportación en la irrigación de Santa Rita de Siguas durante los meses de octubre 2008 a mayo 2009. Tesis para Bachiller. Universidad Nacional de San Agustín, Arequipa, Perú.

Avilan, L., Leal, F. y Baustista, D. (1992). Manual de Fruticultura. Tomo II Editorial AMÉRICA, C.A. $2^{\circ}$ Edición. Caracas, Venezuela. 531 p.

Barnicoat, H., Cripps, R. y Kendon, J. (2011). Conservation in vitro of rare and threatened ferns-case studies of biodiversity hotspot and island species. In Vitro Cellular \& Developmental Biology - Plant 47(1): 37-45.

Hall, R., Holden, M. y Yeoman, M. (1988). Limitaciones al rendimiento del producto en cultivos de rápido crecimiento de Capsicum frutescens. Biochem. Soc. Trans., 16: 66-67.

Hernández, A., Argüelles, A., Cortez, A. y Díaz, H. (2020). Effect of 2,4-dichlorophenoxy acetic concentration on in vitro callus induction using cotyledons of rocoto (Capsicum pubescens Ruiz \& Pav.). The Biologist (Lima) 17(2): $327-334$.

Hernández, A. y Díaz, H. (2019). Inducción in vitro de callo embriogénico a partir del cultivo de anteras en "papa amarilla" Solanum goniocalyx Juz. \& Bukasov (Solanaceae). Arnaldoa 26(1): 277 - 286.

Hernández, A., Pineda, A. y Noriega-Córdova, H. (2019a). Aislamiento e identificación de Fusarium oxysporum obtenidos de zonas productoras de "ají paprika" Capsicum annumm L. (Solanaceae) en el distrito de Barranca, Perú. Arnaldoa 26(2): 689-698.

Hernández, A., Pineda, A. y Díaz, H. (2019b). Efecto de la 
luz y del ácido giberélico en la germinación in vitro de Capsicum annuum L. cv. 'Papri King'. Biotecnología Vegetal 19(3): 165-170.

Jiménez, J., Chaparro-Giraldo, A. y Blanco, J. (2009). Evaluación de diferentes combinaciones fitohormonales en la regeneración de Solanum tuberosum (Solanaceae) Var. Pastusa Suprema a partir de explantes internodales. Rev. Colomb. Biotecnol, XI, 66-74.

Murashige, T. y Skoog, F. (1962). "A Revised Medium for Rapid Growth and Bio Assays with Tobacco Tissue Cultures". Physiologia Plantarum. 15 (3): 473-497.

Ochatt, S. y Caso, O. (1986). Differentials requirements among tissue source in Solanum tuberosum L. ssp. Andigena callus cultures. Turrialba 36: 363-368

Pech, A.M., Castañón, G., Tun, J.M., Mendoza, M., Mijangos, J., Pérez, A y Latournerie, L. (2010). Efectos heteróticos y aptitud combinatoria en poblaciones de chile dulce (Capsicum annuum L.). Rev. Fitotec. Mex. Vol. 33 (4): $353-360$.
Rabindra, S., Varindra, P., Aparna, D. y Gosal, S. (2003). Inducción y proliferación de callos derivados de frutos de diferentes variedades de Capsicum annuum. J. Plant Biochem. Biotech., 12: 159-162

Romero, V. (2018). Eficiencia de Trichoderma viride como un biocontrolador para Phytophthora capsici en el cultivo de pimiento (Capsicum annuum L.). Tesis de ingeniería, Universidad Nacional Agraria La Molina, Lima, Perú.

Sanatombi, K. y Sharma, G.J. (2007). Micropropagation of Capsicum annuum L. Notulae Botanicae Horti Agrobotanici Cluj-Napoca 35: 57-64.

Segretín, M. (2006). Los cultivos celulares y sus aplicaciones II (cultivos de células vegetales). ArgenBio 1 (6)

Valerio, R. (2016). Efecto de la concentración de ácido giberélico en el crecimiento y rendimiento de tres cultivares de pimiento paprika (Capsicum annuum L.). Tesis de ingeniería, Universidad Nacional Agraria La Molina, Lima, Perú. 